Référence : Commenges H., Tomasoni L., Seigneur C., Bonin O., Leurent F., Bonhomme C., Deroubaix J.-F. (2017) "Who is the expert ? Integrated urban modeling and the reconfiguration of expertise", Journal of Urban Technology, vol.24, no2, pp.89-108.

\title{
Who is the Expert? Integrated Urban Modeling and the Reconfiguration of Expertise
}

Hadrien Commenges, Lorenza Tomasoni, Christian Seigneur, Olivier Bonin, Fabien Leurent, Céline Bonhomme, José-Frédéric Deroubaix

\begin{abstract}
Much has been spoken and written about the rationalization and optimization of services and amenities in urban territories. In this context, there is increasing use of numerical modeling techniques addressing the design, selection and/or calibration of policy instruments. The question of the relations between appraisal tools and policy-making has been widely studied. However, few studies have specifically focused on the role of modeling in policy-making processes. Drawing on two case-studies, this paper suggests a change in the nature of multiexpertise: neither conflicting nor cross-sectoral, we observed in both cases an interwoven configuration with a network of experts making use of integrated models. We call this configuration distributed expertise, arguing that it is a novel configuration and that its emergence is closely linked to the development of integrated modeling techniques. Other authors have discussed the idea that the growing need for new appraisal tools is linked with the proliferation of wicked policy problems. From our case-studies we would conclude that the emergence of integrated modeling is not a response to complex problems but to complex systems of actors who need to reach a consensus on actions.
\end{abstract}

\section{KEYWORDS}

Urban modeling; Expertise; Air Quality, Water Quality 


\section{Introduction: Context, Objectives, Scope}

In recent decades researchers have highlighted several emergent features of "city government" or "urban governance" (Brenner, 1998; Lefèvre, 1998; Pierre, 1999), with particular emphasis on mega-city regions (Evers and De Vries, 2013). First, as urban territories expand and become more complex, decision-making systems are becoming institutionally fragmented. Then, much continues spoken and written about the rationalization and optimization of services and amenities in these territories, especially technical networks (transportation, water supply, sewage). Finally, the development of new public management (NPM) - with its focus on efficiency and on tools for measurement and optimization - is closely associated with the governance of cities. For these reasons there is a growing movement to build a new science of cities that could provide tools for the development of the rational city - smart cities with egovernance devices and intelligent transportation systems (Albino et al. 2015; Batty et al., 2012).

This science of cities relies upon numerical modeling techniques geared to the design, selection and/or calibration of policy instruments (e.g. see Lawson, 2006). In this paper, we focus on urban modeling in general, and on integrated urban models in particular. Modeling is defined in a broad sense as the quantitative and selective representation of an object, a phenomenon or a system that may be compared with empirical observations. A model is urban if the phenomena represented are of special importance in the urban context and if, as a matter of fact, the models are mainly applied to urban territories. The model is integrated if it has identifiable coupled components. These definitions will be specified further in order to frame the history of integrated modeling at the urban scale. ${ }^{1}$

There is an increasing body of work dealing with urban modeling in various fields, such as transportation (traffic flow models), sewage (hydraulic models), or the environment (water quality, air quality models). This literature divides into two main perspectives on the function assigned to urban modeling, named after the classical distinction between substantive and procedural rationality (Simon, 1976).

In the first perspective (substantive rationality), the function of modeling methods is to provide rational grounds on which decision-making processes can be based, in other words to guide policy-makers toward a rational decision by identifying which policies might produce optimal outcomes (Ascher, 1981). This technological optimism, shared by most modelers, could be succinctly summed up as: better technology leads to better decisions. In the second perspective (procedural rationality), the function of modeling is to improve decision-making itself. Most of the literature on Decision Support Systems (DSS) falls into this category, arguing that the decision-making process and its outcome (the decision itself) are two linked but separate issues (Shim et al., 2002). Drawing on Simon's description of the decisionmaking process (intelligence, design, choice, implementation), the DSS literature sees modeling as a cognitive crutch that helps reduce the effort required during the decisionmaking process (Todd and Benbasat, 1992). This technological optimism could be succinctly expressed as: better technology leads to better decision-making processes. Both perspectives, especially the first, subscribe to the positivist myth about the role of science and technology in society (Brunner and Ascher, 1992). A large proportion of literature about urban modeling and urban planning is still (neo-)positivist, a paradigm that has been sustained in the last 20 years by the rise of evidence-based policy-making (Clarence, 2002).

Here, we propose a third perspective based on the following premises: 1/ we consider that models have no intrinsic value, they "derive value only from their uses" (Larkey and Sproull, 1981: 236) and 2/ we reject, at least partly, the above mentioned positivist perspectives and recognize, in line with many authors, that technical tools of appraisal, including modeling methods, have limited effect on the policy-making process (Owens et al., 2004). In that case, how can we explain the growing use of models in urban policy-making processes? If they do not ensure rationality in the policy-making process, what use(s) and function(s) justify their 
existence? Part of the answer may lie in depoliticization, as policy is devolved to technical committees equipped with specific quantitative techniques (Flinders and Buller, 2006). However, this explanation remains partial, and a broader answer to these questions is still needed.

The question of the relations between appraisal tools and policy-making has been extensively studied by scholars in the fields of policy sciences and Science-TechnologySociety (Nilsson et al., 2008). However, few studies have focused specifically on the role of modeling in policy-making processes. Some authors have characterized modeling as a bridge between knowledge and action (Batty, 1979; Harris, 1975), but the gap is not yet bridged: modelers focus primarily on the technical aspects of modeling and rarely pay close attention to its use in policy-making, ${ }^{2}$ while policy scientists do pay attention to the use of knowledge in policy-making but rarely focus on modeling techniques as a specific mode of knowledge production. The main objective of this paper is to grasp how models are woven into configurations of expertise, in other words to bridge the gap between the technical operation of a model and its social functions for policy-making.

Our research is rooted in several disciplinary currents or specialties. First of all, we aim to provide a post-positivist but non-relativistic perspective on policy analysis. The positivist myth has been thoroughly deconstructed; we now need to reconstruct knowledge about knowledge, in particular about the use of knowledge in policy-making processes (Collins and Evans, 2002; Fischer, 1992).

In line with many authors in the sociology of science, sociology of expertise, and policy analysis, we assume that technical tools of appraisal - such as modeling methods - play a role in drawing boundaries between science, policy and citizenry (Gieryn, 1983; Jasanoff, 1987). This boundary-work is essential in building the credibility of experts. It contributes to the depoliticization of decision-making by transferring the decision process to technical committees (Burnham, 2001; Flinders and Buller, 2006). Although we acknowledge these insights and draw on the extensive literature on expertise, we are not fully satisfied with this view and we believe that modeling methods play a more immediate role than boundary-work.

In the quest to understand the relations between knowledge production and policy-making, one important contribution is the distinction proposed by Janowitz (1969) between the "engineering" and the "enlightenment" model. Here, the engineering model takes a simple view of applied research, whereby the knowledge producers give the policy-makers direct guidance by identifying and supplying useful knowledge they lack. Whereas, for its part, the enlightenment model takes into account the complexity of policymakers' learning processes: they learn from research findings but through a wide variety of channels, they have to accommodate contradictory research insights, their priorities and timeframes differ from those of the knowledge producers. According to the enlightenment model, knowledge tends to creep into policy-making, gradually altering the background assumptions and concepts that frame the policy-making process (Bulmer, 1981; Weiss, 1987). In line with many authors, we accept that the enlightenment process has a strong long-term effect on policy-making. However, we believe that it constitutes a weak short-term justification for the use of modeling techniques in policy-making.

To sum up our position within the existing literature: 1 / we aim to reconstruct what is known about the uses of knowledge in policy-making processes, 2/ we believe that the function of modeling techniques is not confined to boundary-making, 3/ we are not fully satisfied with the indirect process of long-term enlightenment, so we are looking for a shortterm function that might justify the growing use of models in policy-making. Following Nilsson et al. (2008), we will discuss the widespread view that the growing need of appraisal tools is linked to the proliferation of wicked policy problems. Our discussion is based on casestudies in two policy sectors - air quality, sewage and water quality - and is structured as follows. Section 1 provides a historical background of integrated modeling. Section 2 describes the methodology and the empirical material. Section 3 introduces the notion of 
integrated modeling and its possible impacts on configurations of expertise. Section 4 focuses on the functions of integrated modeling within a group of experts. Section 5 studies how confidence in the model is established and shared within the group of experts.

\section{The Novelty of Integrated Modeling Platforms}

At the urban scale, the development and use of integrated models has followed a complicated path. A first stab at integration was attempted in the 1960s with the so-called comprehensive models developed to support comprehensive planning (Chapin and Kaiser, 1979). This decade has since been described as rich and intense in terms of modeling techniques, and disappointing with regard to the use of models in policy-making (Goldner, 1971). Lee (1973) wrote a famous "requiem for large-scale models" predicting their extinction. Several papers, including Lee's requiem, tried to explain the failure of comprehensive models from a technical perspective: the models suffered many defects, they were costly to develop, to validate, and to maintain. Few authors really examined the use of models within the planning process, with two notable exceptions: Gary Brewer (1973) and Janet Pack (1975; 1977). Brewer conducted a detailed analysis of two case-studies (San Francisco and Pittsburgh), reaching an organizational conclusion: the failure of comprehensive models lay in the dissociation between the modelers' efforts and the users' expectations: "to the extent that it [the model] could answer questions, they were questions that nobody was asking” (Brewer, 1973: 165).

A few years later, Pack undertook a quantitative, questionnaire-based analysis of the use of models in nearly 1500 U.S. planning agencies. This study came to a different conclusion: many agencies were model users and/or developers, the users found the models useful, and the survey revealed a growing tendency to develop and use models. In a special issue of the Journal of the American Planning Association published in 1994, several authors (Batty, 1994; Harris, 1994; Wegener, 1994) looked back to this dispute and concluded that Lee's requiem was short-sighted. Once again, their reasoning was technical: rapid advances in theory, in computer technology and in data production had invalidated Lee's reasoning and conclusion. However Pack took a more nuanced view and recognized that the assessment of the utility of modeling was incomplete: "the evaluations themselves raise some interesting questions; in particular the very widespread evaluations of the models as 'very useful'. Given the quite different general impression we derive from the literature on model use and usefulness, this finding suggests that further probing of what is meant by usefulness is required" (Pack, 1975: 198).

This account raises three important points. First, it is not possible to establish unambiguous conclusions about the use or non-use of comprehensive models in the 1960s1970s, for several reasons: the literature on the use of models for urban policy-making is small, focusing on urban planning and leaving out a very wide range of urban policies, and it relies almost exclusively on US case-studies. In France, for example, we know that such comprehensive models were not used during this period (Dupuy, 1978).

Second, in this small body of work we found only a single study (Brewer, 1973) based on actual observation of urban models in use. Moreover, in these studies on the "use", the "usefulness", the "role", and the "function" of modeling, there is no conceptual effort to define these key words, as Pack acknowledged. Such studies came later, with Weiss's studies of the uses of social research in public policy making $(1977 ; 1980)$ or Dunn's general classification of the uses of knowledge (1983). Overall, such studies were rare before the creation of the journal Knowledge in 1979.

Finally, there is no formal definition of the term "integrated model" and the literature preferentially uses the term "comprehensive model" to refer to models with land usetransportation integration (LUTI). Voinov and Shugart (2013: 149) recently proposed a community-based definition of integration. An integrated model "bring[s] together diverse 
types of information, theories and data originating from scientific areas that are different not just because they study different objects and systems, but because they are doing that in very different ways, using different languages, assumptions, scales and techniques.” Under this definition, the comprehensive models of the 1960s and 1970s cannot be considered integrated.

In conclusion, there is no evidence that decision-making supported by integrated urban models existed prior to the 1990s (Voinov and Shugart, 2013). By giving different scientific communities a common interface, the development of geographic information systems (GIS) has probably played a role in the development of integrated modeling platforms (Johnston and de la Barra, 2000), but further research is needed on this subject. It would be interesting to explore the causes of the emergence of integrated urban models. It would also be interesting to investigate the chicken-and-egg question associated with the recent coexistence of integrated modeling and distributed expertise: does the technical advance (integrated models) produce organizational change (distributed expertise) or vice versa? Rather than addressing these questions, however, we will focus on the forms of coexistence between the technical and organizational aspects.

\section{Methodological Background and Empirical Application}

This research is based on two case studies (see Fig.1): the revision of the Île-de-France region's Atmospheric Protection Plan (PPA $)^{3}$ and the revision of the Paris conurbation's Sewage Master Plan (SDA) ${ }^{4}$.

The PPA revision process is conducted by the decentralized technical services of the Ministry of Ecology, Sustainable Development and Energy for the Île-de-France region (DRIEE) $)^{5}$ and involves several types of organizations: local authorities, an engineering consultancy firm and a para-governmental organization contracted for air quality monitoring. The PPA establishes a set of regulatory measures, such as the capacity to impose traffic restriction (alternating traffic) or to control wood-fired heating systems.

The SDA revision process is conducted by the organization of local authorities for the Paris conurbation's sewage system (SIAAP) ${ }^{6}$ and involves the local authorities of Paris and three suburban districts, the Seine-Normandie Water Agency responsible for water supply and wastewater management for the whole watershed, as well as two engineering consultancy firms. This masterplan establishes regulatory measures but its main purposes to plan the modernization of the sewage infrastructure (collectors, wastewater treatment plants).

There are several reasons for the choice of these two case-studies. First, air quality and sewage are particularly problematic in urban areas. Second, it is interesting to compare observations from two different spheres: whereas wastewater treatment has historically been primarily a matter of infrastructure planning, there is no specific infrastructure for air quality, which means that the PPA deals exclusively with regulatory measures. While modeling has played a historical role in the planning of urban infrastructure, we wanted to explore what kind of use it may have in a sector without infrastructure. Finally, to compare the uses of modeling in different sectors and plans, we wanted to stay as far as possible within a unified territory, the Paris metropolitan area (see Fig.1). 
PPA

Plan of Protection of the Atmosphere Plan de Protection de l'Atmosphère

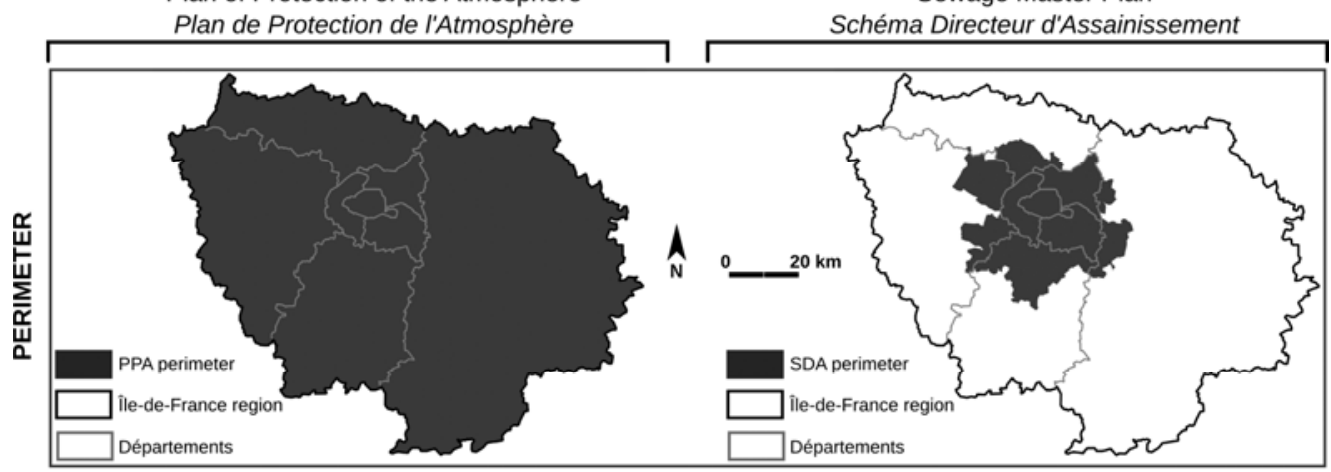

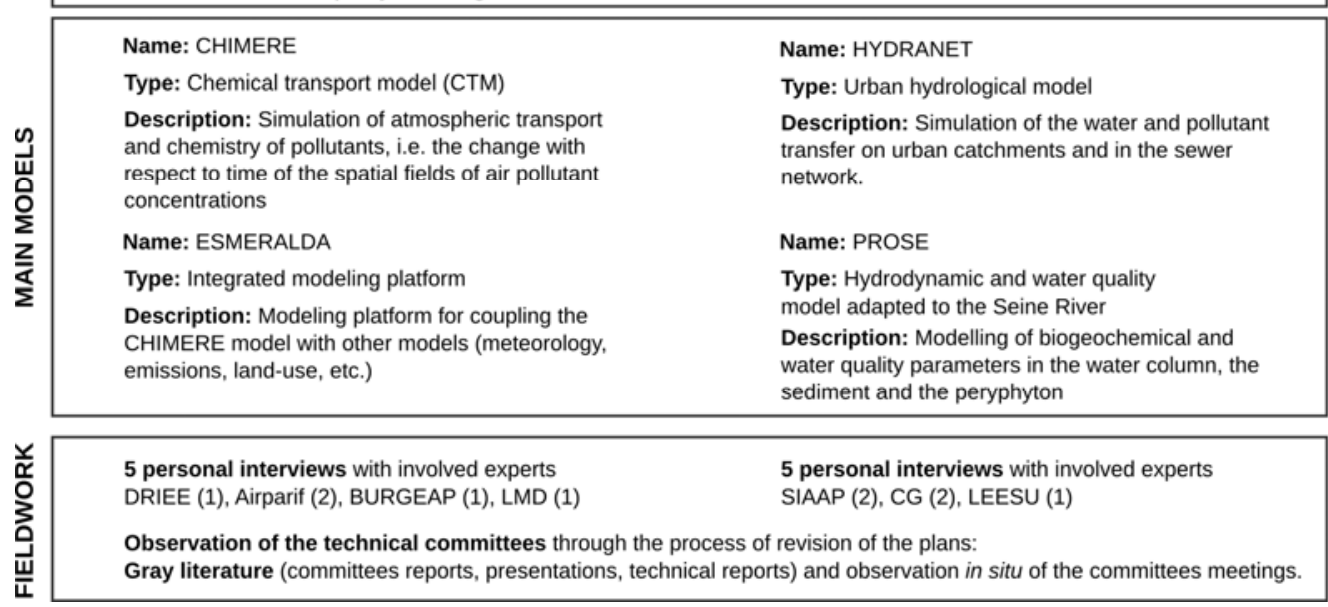

Figure 1: Summary of the case-studies: perimeter, actors, models, fieldwork. Source: Authors.

The case-studies are analyzed using three main kinds of observation materials: observation of the technical committees meetings; personal interviews with people involved in these technical committees; analysis of the corresponding gray literature (minutes of meetings, public communication documents, technical documents such as model specifications or model outputs).

Methodologically speaking, the present research draws on several approaches, mainly ethnographic, and our observation was as far as possible naturalistic. With respect to the STS field, our work is inspired by the sociology of translation case-studies. In fact, the best way to grasp the function of models within policy-making processes is to focus on the interaction between models and people involved in the policy process and to observe this interaction "in action" (Latour 1987). The fieldwork was conceived to this end: we take nothing for granted but pursue "anthropological strangeness" (Latour and Woolgar, 1979: 30), in other words an 
attitude that treats the work of the technical committees as the customs of an unfamiliar community. Just like the laboratory life studied by Latour and Woolgar, the life of the technical committees is driven by inscriptions. We need to track those inscriptions (records, tables, graphs, maps) from their production to their uses, by analyzing:

- the inscription in itself,

- the mode of production of these inscriptions through modeling techniques or observation,

- the way these inscriptions are used within technical committees,

- the way they are used to establish links between the technical and political actors,

- the way they are used to establish links between the technical actors and citizens.

In our case-studies, the only traces we saw of the modeling work were outputs of the model, i.e. written and graphical materials: records, tables, graphs, maps, and drawings. Except for the model users and developers, most of the actors concerned had, like us, seen only written and graphical material. That is why the study of inscriptions is the most relevant way to grasp uses of the model: only the graphical traces of the model, not the model itself, are used in the policy process.

We conducted a systematic content analysis of the personal interviews, of the transcriptions of the committee meetings and of the gray literature, and we tried to adopt a behaviorist stance, i.e. to focus on what can be observed without looking for hidden meanings. It is especially interesting to compare observations of the committees with the post-produced materials, such as interviews and committee reports. This comparison is a way to detect ex post facto interpretations (Mills, 1940). In our interviews, we asked naive questions such as "What is the utility of models?" or "What functions would you say you have in the process?", without ever defining keywords such as utility or function. Because these words are both taken for granted and polysemous, they are fuzzy, and we wanted to observe what meaning each interviewee would ascribe to them. Here, we will not specify preliminary meanings from the start, but instead propose operational definitions as we progress through the analysis. The proposed definitions are operational in the sense that they are derived from observations of our case-studies and are useful in interpreting those observations.

\section{Integrated Modeling and Distributed expertise}

In our case-studies we observed a division of labor and a division of stages in the modeling process: 1 / determining actions to assess and 2/ assessing those actions with models. In both cases, the technical committees conducted an iterative sequence in both stages. The main difference lies in the objectives. With regard to the sewage system and water quality, the SDA follows national and European legislation, mainly the European Water Framework Directive (OJEU, 2000), which establishes criteria of "good status" for all water bodies. The SDA's measures are conceived in order to achieve the legal target values. For air quality, the PPA also operates within a legal framework, both national and European (OJEU, 2008), which establishes target values and alert thresholds, but the PPA's actions in this case are not conceived as a direct method of attaining these regulatory target values.

In the PPA revision, the first task (determining actions to assess) falls to BURGEAP, a consultancy firm; the second task (assessing those actions) falls to Airparif, the air quality agency for the Île-de-France region. Beyond the neat official division of roles, observation of the technical committees and the interviews with the staff of both entities revealed a fuzzy process of consensus formation:

Interviewee (BURGEAP): there is the upstream part of the study; it aims to reach a collective commitment on the actions. We organize working groups to determine which actions might be relevant, who might be in charge, on what technical and legal grounds. Once all the actors concerned agree on these actions, we begin to construct scenarios and the modeling task. 
This upstream component, based on a variety of preliminary studies, generates a set of anonymous actions for assessment. We also observed this process of anonymous consensus building in the SDA revision process. Even with all the relevant raw material and gray literature, it is often impossible to trace the authorship of the proposals. If a proposal does have a clear author, this information sometimes appears in the committee report and then totally disappears from the plan.

At first sight, these preliminary observations are not specific to decision processes supported by modeling. Analyzing our material, we found that the modeling element of the process intensifies the fuzziness and anonymity of the configuration of expertise. In the PPA revision process, air quality is forecast for a future year (2020) with the ESMERALDA platform (see Fig.2), which is described as an inter-regional integrated modeling platform. This platform is the outcome of cooperation between six air quality monitoring organizations, two research institutes (LMD, INERIS) and two national agencies, one for the environment and energy management (ADEME) and the other for weather forecasting (Météo-France). In this process, CHIMERE is presented as the only model in use, the rest being presented as input data. Behind this apparent simplicity, there are in fact several sector-specific models: the air pollutant emissions are generated through a traffic model and an emissions model; weather forecasts and regional pollution are also the outputs of models; the population data are generated by a demographic land-use model; the link between "observational data" and "spatialized indices" hides a process of data assimilation that is a modeling technique in itself. Overall, forecasting air quality for the PPA involves at least seven distinct models and six organizations producing model outputs and/or observational data in at least four distinct fields: air pollution, weather, demography-geography, and traffic. This picture does not take into account the preliminary studies used to prepare the forecasting, though they also rely on modeling techniques. In the case of the PPA for example, a specific study headed by Airparif and LSCE, a research laboratory, highlighted the importance of wood-fired heating systems for emissions of particulate matter (PM).
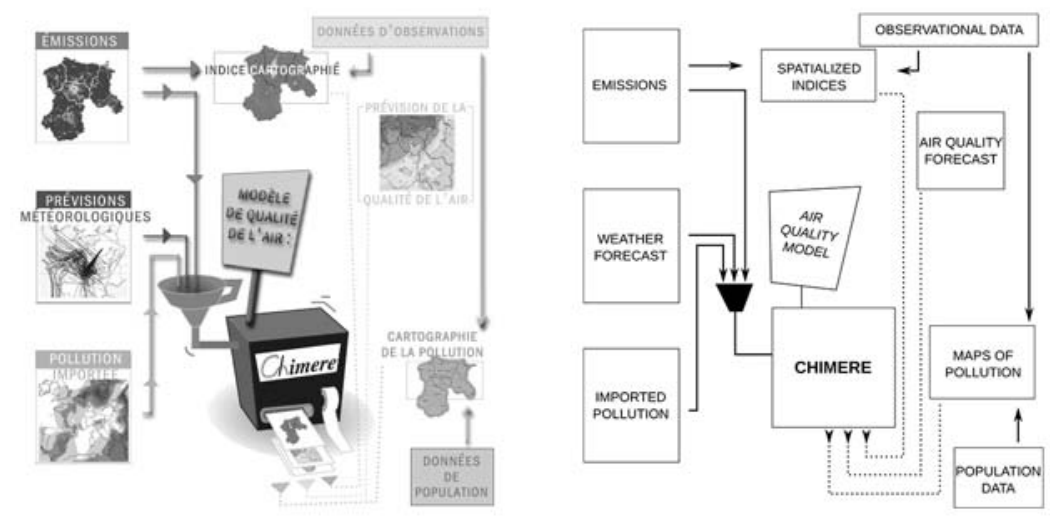

Figure 2: The ESMERALDA platform for air quality forecasting. Source: adapted by authors from the ESMERALDA Project (http://www.esmeralda-web.fr)

The case of the SDA revision process is less complicated but explicitly involves at least three models: a hydraulic model, a water quality model, and a demographic land-use model. In this particular plan, climate is kept constant so there is neither climate forecasting nor rainfall modeling. Just as in the PPA case, however, there are other models used in preliminary studies but not accounted for, for example relating to endocrine disruptors or ecological continuity. 
In addition, the committee report plays a role in the process. Seen as a tool for tracking ideas, opinions, and discussions, the report appears to be a tool of retrospective consensus making. By comparing the observations of the committees and what remains in the committees reports, we found a clear tendency to enhance the points of agreement and to smooth out the areas of conflict. In the SDA revision process, several heated debates took place about the gap between the outputs of the model and empirical knowledge of the sewage infrastructure. One of these discussions lasted 17 minutes: a local sewage manager, with support from another, pointed to a huge difference between the model outputs and the observational data, criticized the method and asked for other tools for comparing predictions and data. In this discussion, he expressed highly critical opinions with explicit vocabulary: "it is a fiction...", "I think we should reconsider...", "there is an omission or an error...”. On the other side, the representatives of the water management organization (SIAAP) and the consulting company tried to defend the work, looking for consensus. Most of their sentences took a "yes...but" structure: "yes, but you have a local vision", "yes, we should keep a critical eye on the model but...", "I understand, but I have a problem with your proposal". The committee report gives a very short summary of the event with no markers of controversial issues. Discussion is eradicated from the report, which becomes a smoothing-out exercise, contributing to the formation of an anonymous and consensual set of actions to assess.

Let us sum up the process: 1 / an anonymous and consensual set of actions is determined, and $2 /$ those actions are assessed through an integrated platform of interwoven sector-specific models. This two-step sequence (choice and assessment) is reiterated until a coherent and agreed-upon package of actions is reached. We underscore the nature of our case-studies: ex ante conception and design of policies and not multi-criteria ex post appraisal. From a classical Lasswellian perspective, policy scientists have explored different configurations of multi-expertise within the policy process: situations of consensual and (mostly) conflicting expertise, specialized or cross-sectoral expertise. In the latter case, the cross-sectoral expertise is the juxtaposition of sector-specific expertises and it is the role of the policy scientist to elicit and synthesize the relevant knowledge (Lasswell 1971). In each of these cases, there is a clear correspondence between a piece of expert knowledge and its author. Scientific endorsement and expert responsibility can be easily traced. Our case-studies suggest a change in the nature of multi-expertise: it is neither conflicting nor cross-sectoral, but interwoven. We call this novel configuration distributed expertise. It is characterized by a neat distribution of roles in theory and a fuzzy distribution of roles in practice.

In the following sections we will argue that the emergence of distributed expertise is closely linked to the development of integrated modeling techniques. For now, this configuration has an immediate consequence: the disappearance of the expert as an individual or an organization and the emergence of the expert as a network of individuals and/or organizations.

\section{The Functions of Integrated Modeling}

Both case-studies show a close interweaving of sector-specific actors responsible for sectorspecific models. The modeling stage of the policy-making process consists of a coupling of several models in the SDA case-study and of a fully integrated modeling platform in the PPA case-study. This section aims to address the main question of this paper: what are the links between integrated modeling and distributed expertise?

We first need to clarify some key concepts: use, usefulness, function. Regarding the term use, we draw on the classification of knowledge use proposed by Dunn (1983). It consists of a cross-classification with three dimensions: the use may be for individual or for collective decision-making; its effects may be conceptual (user conception) or behavioral way (user observable behavior); it may be applied to a general or a specific problem. When the three 
binary pairs are combined, we end up with eight possible types of uses. Janowitz's two models, mentioned above, are included in Dunn's classification as:

- Individual-behavioral-specific (“decisional use”): operational knowledge is used to provide direct guidance for the policy-maker.

- Collective-conceptual-general (“enlightened use”): knowledge tends to creep into policy making, gradually altering the background assumptions and concepts that frame the policy-making process.

The classification proposed by Dunn is an important step towards clarifying the different uses of knowledge for policy-making. Yet it is still unclear how the notion of use is linked to the notion of usefulness. When a knife is used to slice vegetables, the use and the usefulness of the knife can be considered as one and the same. Use and usefulness are coupled because there is one person, one tool, one action, and also because there is immediacy of intention, action and result. When a technical committee uses a modeling platform to contribute to a policy-making process, things are more complicated (several actors, several actions, several moments) and the two notions are decoupled. First, if you ask about the usefulness of the model, the answer may differ according to the position of the interviewee within the policymaking process. Then, when asked about the usefulness of the model, the interviewee always looks for a "behavioral" and "specific" justification, in Dunn's terms: he/she will never answer: "the model tends to creep into policy-making, gradually altering the background assumptions and concepts that indirectly affect the policy-making process." For all these reasons we need to complete the notion of use by distinguishing different levels of interpretation.

In the interviews conducted in both case-studies, the interviewee often says "the model is useful for..." or "the model is used to..." meaning "I/we used the model for..." Because of this observed ambiguity, we call this usefulness. Usefulness is defined as the ex post facto interpretation of the use by the user. But we need another term to speak about uses from our perspective, which is function. Function is defined as the ex post facto interpretation of the use by the observer (us). The distinction between usefulness and function is important if we are to understand the life cycle of a model. If there is some kind of struggle over a model - using one model rather than another, using or not using any model- the use and survival of a model over time is due to its function and not to its usefulness. The terms have a relation of inclusion: usefulness is narrower, it is a part of function. For example, the enlightenment mentioned in the introduction is considered as function, not usefulness.

From the observation of our case-studies, we detected two different functions of integrated modeling within the configuration of expertise: scoping and channeling. A third possible function - consolidating - is discussed in the conclusion.

Scoping means setting a neat demarcation line in the scope of expertise and fixing the identity and the role of the actors concerned. In the previous section, we described a reiterated, two-stage process: setting up actions and assessing them by means of modeling. We told a simplified story, as if the setting up were a free and autonomous operation. In fact, it depends on the actors enrolled in the network (and their authority) and it also depends on the modeling stage. In both the PPA and in the SDA revision processes, we noticed several examples of scope alignment. We restrict our observation to the notion of scope and do not consider the notion of frame defined as "underlying structures of belief, perception, and appreciation" (Schön and Rein, 1994: 23). In both case-studies, the actors concerned have fairly homogeneous frames and we noticed no frame conflicts or reframing operations.

In the PPA for example, one potentially important source of emissions is cooking, which affects both indoor and outdoor air quality. As these emissions are not currently included in French emission inventories, their impacts on air quality cannot be assessed, and there is therefore no reason to incorporate any action on cooking emissions and no reason to enroll specific actors - such as the food service industry - into the network. Actions and actors are 
excluded from the scope if a corresponding lever for action cannot be incorporated into the integrated modeling platform.

Another potentially important source of emissions is the agriculture sector, which is nevertheless barely mentioned in the PPA. The interviewee from the DRIEE explains:

Interviewee: Initially, we had planned substantial actions for the agriculture sector but they [the Ministry] made it clear that we couldn't expect anything from the farmers on air pollution. Firstly, they already have to deal with other types of pollution, ground and water pollution. And secondly, it is a very tricky economic sector.

As a matter of fact, the farming sector is not represented in the network of actors concerned; the PPA plan only includes a soft measure - limits on fertilizer application depending on wind speed - which was not assessed within the modeling platform.

In the SDA we observed a long discussion (28 min) on the advantage of testing scenarios with varying levels of impermeability. Impermeability affects the sewage system and water quality at different levels: more impermeable surfaces result in larger runoff volumes. When rain falls, dry weather deposits (oil, gasoline, heavy metals, fertilizer, pesticide) are washed into the sewage infrastructure and water bodies. None of the actors in the network of expertise had authority to enact the relevant measures on this issue, so there was no assessment of impermeability actions.

To sum up: 1/ An action that cannot be modeled is excluded from the set of actions to assess and the corresponding actor is not included (cooking case). 2/ The prior exclusion of a potential actor is reflected in exclusion from the set of actions and from assessment in the model (agriculture sector case). 3/ A relevant measure that is outside the authority of the actors concerned is not modeled and not taken into consideration (impermeability case). Overall, what we see is an alignment in the identity of the actors concerned, in their authority, in the set of actions to be assessed, and in possible inputs into the model. The integrated modeling platform has a function in this alignment: it links the potential actors and the potential actions and defines the scope of the network.

Another function that emerged from the analysis of the case-studies is channeling, i.e. how the modeling exercise channels discussions within the network. The existence of an integrated modeling platform helps to sharpen the process and the target of assessment. It has indirect procedural efficacy, as defined in the introduction. A key concept needed to describe this function is drawn from Garfinkel's work: indexicality. Indexicality explains how a "working consensus" is reached in a conversation where there are always irreducible differences in meanings between the speakers-listeners. In an everyday conversation, the speaker assumes that the listener shares the same meanings. This assumption may lead to fuzzy and frustrating discussions when the subject of conversation is clearly framed: "indexical expressions [...] present immense, obstinate, and irremediable nuisances to the tasks of dealing rigorously with the phenomena” (Garfinkel, 1967: 6). In our case-studies, we noticed that when a conversation becomes fuzzy, the people involved in it end up making references to the model: its inputs, its entities, its mechanisms, its outputs. In the SDA casestudy, the model provides a common vocabulary that allows discussion between the different communities: the Water Agency experts with their global view, the consultancy firm modelers with their abstract perspective, and the local sewage managers with their pragmatic angle. The model acts as a boundary-object: it bridges separate communities and practices by providing a body of modular and standardized information (Star and Griesemer, 1989; Wenger, 2000).

In conclusion, we observed a configuration of distributed expertise, we argued that this configuration was relatively new, and we analyzed the coexistence of integrated modeling and distributed expertise. The network of interwoven models and actors described needs trust to maintain its robustness. In the STS field, many authors have studied the nature and role of trust in the relations among experts, government agency representatives and citizens. In philosophy and sociology of science, many authors have studied the role of trust among scientists (Whyte and Crease, 2010). However, there is little in the literature on the 
establishment of trust within a network of multiple experts. Yet it is a necessary condition for the survival of the network.

\section{The Social Validation of the Model}

Since the early development of numerical models after World War II, modelers have built normative definitions of key terms like verification, validation, or calibration (Nance and Sargent, 2002). Verification is the establishment of truth: a verified model is a truthful model, that is, an accurate representation of reality. In the case of computer models of social and/or physical systems, veracity can never be established. The truth of a proposition can only be established in a closed formal system and not in a complex open system where the input parameters are empirically calibrated (Oreskes et al., 1994). Validation is the establishment of trust: a valid model is a model whose results match empirical data within a predefined acceptable range of error. Although this definition has been criticized (Konikow and Bredehoeft, 1992), it is a reasonable characterisation, widely used in some communities. However, the criteria used in the air quality and water quality communities are more stringent. First, since the agreement between model outputs and observations can be fortuitous (for example because of error compensation), they instead refer to the performance evaluation rather than validation of a model; in this case, a model shows acceptable performance if the agreement between the model's output and the observations falls within pre-determined bounds. Second, a distinction is made between various types of evaluation, in particular between operational and dynamic evaluations (Seigneur et al., 2000; Dennis et al., 2010). Operational evaluation, which refers to a model's ability, for example, to reproduce measured concentrations of regulated air pollutants, is of limited use since the model is typically used to estimate the change in those air pollutant concentrations resulting from a change in air pollutant emissions or a change in weather conditions. Dynamic evaluation, which pertains to the model's ability to reproduce such changes, is then needed to give the desired credibility to the use of the model in the investigation of future air quality.

An interesting point is the frequent confusion between verification and validation. It is not uncommon for modelers - and even more so model users who are not modelers - to make statements of the kind: the match between predicted results and observed data (validation) means that the model is a good representation of reality (verification). In our case-studies we found many assertions reflecting this confusion in utterances by researchers, practitioners, and the technical staff of the agencies.

We will not focus here on the epistemological approach to validity and validation. Instead, we aim to propose a sociological approach based on observation of the uses of models within the policy-making process, built through an inductive content analysis. It was first revealed by an interesting case relating to emission factors in the quarrying industry (PPA revision) and confirmed by the analysis of the materials produced in the second case-study (SDA revision).

In the first version of the PPA, the modelers used a single national emission factor for stone quarries. According to the air quality model, this small industrial sector was producing $10 \%$ of the total particulate emissions in the Île-de-France region. After looking at US literature on the subject, the modelers came to the conclusions that: $1 /$ the emission factors could vary greatly between stone types and $2 /$ the emission factor used for the whole country related to dry rocks quarries, whereas there are no such quarries in the Île-de-France region. This meant that the quarrying industry's emissions were overestimated by a factor of 1000 . The DRIEE interviewee explained:

Interviewee: With Airparif we alerted the ministry and they asked CITEPA [the organization responsible for the development of national emission inventories for the ministry] to produce more accurate emission factors for the quarrying industry. A working group was set up and proposed emission factors disaggregated into 3 or 4 quarry types. Without this work by CITEPA, we would not officially be able to take this emission factor into 
account, because Airparif can only use factors that have been approved by all the actors. In this case, it was proposed at the national level, so it was reliable.

For the lead person in the lead entity, the reliability of the data depended not on the experimental conditions of production, but on a consensus and trust given a priori to the actor in charge. During the interview, this confusion was extended to the notion of validity:

Interviewee: When we have accurate localized emission factors, based on a regional study, we can use these emission factors, but they must be validated, that is, the study should be approved by all the actors in the Île-de-France region.

Interviewee: We don't have the skills to impose detailed specifications regarding the use of one model rather than another. We trust them [Airparif]. We just make sure that the models are approved, validated, we set constraints only for the result, not for the method.

The interviews with Airparif's technical staff - the model users who run the model, test the scenarios and produce the outputs required by the DRIEE - showed cascading responsibility regarding the reliability of the model's output. Once again, reliability is expressed in terms of trust:

Interviewee: We did not change the weather forecasting or the chemistry of the model. We use the model, we don't make changes to the chemistry of the model, we trust it...

Interviewer: and you also developed it? Who develops the CHIMERE model?

Interviewee: IPSL, LMD and INERIS [three research institutes]

The interviews with LMD researchers - the model developers - closed the loop: cascading responsibility became tautological:

Interviewer: can we say that CHIMERE is a reliable model which can support decisions?

Interviewee: yes, certainly, it is used everyday to forecast air quality; it is certified ("labellisé") by the ministry.

This answer contains two statements: a proof by use - the model has proved its worth through continuous utilization - and a faith-statement involving trust in another actor in the process: if the ministry trusts it, it must be trustworthy. So, who is responsible for the reliability-validity of the model? We have just qualified the distribution of responsibility as cascading, then tautological; we now propose the term systemic responsibility to qualify the self-bestowed trust within a network of actors. From this definition, we propose a social definition of validity and validation. A valid model is an approved model. Social validation is the establishment of consensus regarding the use of the model, i.e. the establishment of systemic responsibility between the actors involved.

Of course, the CHIMERE model has been subjected to technical validation procedures (operational and dynamic performance evaluations) and has shown acceptable performance. In different communities of modelers, technical assessment of the model (validation, performance evaluation) is generally believed to be both necessary and sufficient before its use in policy-making. We conclude from our case-studies that both the technical and social validations of the model are necessary and neither is self-sufficient. Social validation in particular is needed in a configuration of networked expertise based on integrated models.

In both case-studies, sector-specific policy communities were built before and outside the observed policy-making processes (Deroubaix, 2007). The establishment of trust among the actors during the policy-making process should be seen as a specific moment in the building of a policy community.

\section{Conclusions and further Research}

The main objective of this work was to grasp the interweaving of models into configurations of expertise, bridging the gap between the technical functioning of a model and its social functions for policy-making.

First of all, our two case-studies suggest a change in the nature of multi-assessment: neither conflicting nor cross-sectoral, in both cases we observed an interwoven structure with 
a network of experts making use of integrated models. We have called this configuration distributed expertise, arguing that it is a novel configuration and that its emergence is closely linked to the development of integrated modeling. Other authors have discussed the idea that the growing need for new appraisal tools - such as integrated modeling - is linked to the proliferation of wicked policy problems (Nilsson et al., 2008). From our case-studies we would conclude that the emergence of integrated modeling is a response not to complex problems but to complex systems of actors who need to converge in favour of consensual action. Is integrated modeling reflective of the emergence of complex systems of actors or do integrated models help to create and maintain the configuration of such complex sets of actors? As commonly happens with chicken-or-egg problems, both assertions are probably valid but we focus here on the second: because we wanted to observe committees in the act of using models, we chose case-studies with existing sets of actors.

Then, from the observation of our case-studies, we detected two different functions of integrated modeling within the structure of distributed expertise: scoping and channeling. 1/ The model sets a neat demarcation line for the scope of the assessment. 2/ It facilitates and channels the discussions within the network allowing the building of a "working consensus". In this sense, the model acts as a boundary-object bridging distinct communities and practices. Finally the integrated modeling platform may have the function of consolidating the assessment and combating new tendencies that may be perceived as threats: the dispersal and/or democratization of expertise (Maasen and Weingart, 2005). We propose this function as a hypothesis that would merit further research.

Finally, we observed a process whereby the model received social validation and proposed the term systemic responsibility to qualify the trust self-bestowed within a network of actors. While technical assessment of the model is often believed to be necessary and sufficient before it is used in policy-making, we claim that technical and social validation of the model are both necessary and neither is self-sufficient.

The establishment of trust is especially important in a configuration of networked expertise based on integrated models. In fact, it is the main problem that our study addresses. At the very foundation of expert assessment, there are two premises: 1/ scientific endorsement and expert responsibility can easily be traced, and 2/ there is a clear correspondence between expert knowledge and its author. In a network of experts who construct assessments with an integrated modeling platform, neither of these premises is true. This conclusion, drawn from two case-studies, needs further research as it opens up important questions regarding the evolving nature of expertise.

\section{Ackowledgments}

Two postdoctoral fellowships were funded by the LabEx program "Urban futures".

\section{Note on contributors}

Hadrien Commenges is a postdoctoral fellow at the Laboratoire Eau, Environnement et Systèmes Urbains (Water, Environment, and Urban Systems Laboratory). His research focuses on the history of urban modeling and its uses in policy-making processes.

Lorenza Tomasoni is a postdoctoral fellow at the Laboratoire Eau, Environnement et Systèmes Urbains (Water, Environment, and Urban Systems Laboratory). She investigates the conception and use of indicators for urban planning and transportation.

Christian Seigneur is the director of the Centre d'Enseignement et de Recherche en Environnement Atmosphérique (Atmospheric Environment Center). Previously, he was vice president and head of the Air Quality Division at Atmospheric \& Environmental Research Inc. in the San Francisco Bay Area. His research activities address the multi-scale modeling of air pollution. 
Olivier Bonin is the deputy director of the Laboratoire Ville Mobilité Transport (City, Mobility, Tranportation Laboratory). His current research focuses on geographical information, spatial analysis and geographic modeling of urban areas.

Fabien Leurent is the deputy director of the Laboratoire Ville Mobilité Transport (City, Mobility, Tranportation Laboratory). His main research areas concern operational research and systemic modeling, mainly in the field of urban transportation and housing.

Céline Bonhomme is a researcher at the Laboratoire Eau, Environnement et Systèmes Urbains (Water, Environment, and Urban Systems Laboratory). Her research currently focuses on the transfer of traffic pollutants in urban water bodies.

José-Frédéric Deroubaix is a researcher at the Laboratoire Eau, Environnement et Systèmes Urbains (Water, Environment, and Urban Systems Laboratory). His research activities address the interaction between the production of knowledge and the production of expertise, mainly in the fields of sewage and water quality.

\section{References}

M. Akrich, "The De-scription of Technical Objects,” in W. Bijker, J. Law, eds., Shaping Technology, Building Society: Studies in Sociotechnical Change (Cambridge: MIT Press, 1992).

V. Albino, U. Berardi, R.M. Dangelico, "Smart Cities: Definitions, Dimensions, Performance, and Initiatives," Journal of Urban Technology, 22:1 (2015) 3-21.

C.A. Andrews, "Rationality in Policy Decision Making," in F. Fischer, G.J. Miller, M.S. Sidney, eds., Handbook of Public Policy Analysis (New York: CRC Press, 2007).

W. Ascher, "The Forecasting Potential of Complex Models," Policy Sciences, 13:3 (1981) 247-267.

M. Batty, K.W. Axhausen, F. Giannotti, A. Pozdnoukhov, A. Bazzani, M. Wachowicz, G. Ouzounis, Y. Portugali, "Smart Cities of The Future," European Physical Journal Special Topics, 214 (2012) 481-518.

M. Batty "A Chronicle of Scientific Planning: The Anglo-American Modeling Experience," Journal of the American Planning Association, 60:1(1994) 7-16.

M. Batty "Progress, Success, and Failure in Urban Modeling," Environment and Planning A, 11 (1979) 863-878.

N. Brenner "Global Cities, Glocal States: Global City Formation and State Territorial Restructuring in Contemporary Europe,” Review of International Political Economy, 5:1 (1998) 1-37.

G.D. Brewer, Politicians, Bureaucrats, and the Consultant: a Critique of Urban Problem Solving (New York: Basic Books, 1973).

R.D. Brunner, W. Ascher, "Science and Social Responsibility,” Policy Sciences, 25:3(1992) 295-331.

M. Bulmer, "Applied Social Research. A Reformulation of 'Applied' and 'Enlightenment' Models," Knowledge: Creation, Diffusion, Utilization, 3:2(1981) 187-209.

P. Burnham, "New Labour and The Politics of Depoliticisation," The British Journal of Politics \& International Relations, 3:2(2001) 127-149.

M. Callon, "Éléments pour une sociologie de la traduction : la domestication des coquilles Saint-Jacques et des marins-pêcheurs dans la baie de Saint-Brieuc," L'Année sociologique, 36(1981) 169-208.

F.S. Jr. Chapin, E.J. Kaiser, Urban Land Use Planning, 3rd ed. (Urbana: University of Illinois Press, 1979).

E. Clarence, "Editorial. Technocracy Reinvented: the New Evidence Based Policy Movement," Public Policy and Administration, 17:3(2002) 1-11.

H.M. Collins, R. Evans "The Third Wave of Science Studies: Studies of Expertise and Experience," Social Studies of Science, 32:2(2002) 235-296. 
R. Dennis, T. Fox, M. Fuentes, A. Gilliland, S. Hanna, C. Hogrefe, J. Irwin, S.T. Rao, R. Scheffe, K. Schere, D. Steyn, A. Venkatram, "A Framework for Evaluating RegionalScale Numerical Photochemical Modeling Systems,” Environmental Fluid Mechanics, 10(2009) 471-489.

J.-F. Deroubaix, "The Co-Production of a 'Relevant' Expertise. Administrative and Scientific Cooperation in the French Water Policies Elaboration and Implementation,” Hydrology and Earth System Sciences, 4(2007) 3771-3792.

W.M. Dunn, “Measuring Knowledge Use," Knowledge: Creation, Diffusion, Utilization, 5:1(1983) 120-133.

G. Dupuy, G., Urbanisme et technique: chronique d'un mariage de raison (Paris: Centre Technique de l’Urbanisme, 1978).

D. Evers, J. De Vries, "Explaining Governance in Five Mega-City Regions: Rethinking the Role of Hierarchy and Government," European Planning Studies, 21:4(2013) 536-555.

F. Fischer, "Response. Reconstructing Policy Analysis: a Postpositivist Perspective," Policy Sciences, 25:3(1992) 333-339.

M. Flinders, J. Buller, "Depoliticisation: Principles, Tactics and Tools," British Politics, 1(2002) 293-318.

J.W. Forrester, "System Dynamics: a Personal View of the First Fifty Years," System Dynamics Review, 23:2-3(2007): 345-358.

H. Garfinkel, Studies in Ethnomethodology (Englewood Cliffs: Prentice-Hall, 1967).

T.F. Gieryn, "Boundary-work and the Demarcation of Science from Non-science: Strains and Interests in Professional Ideologies of Scientists," American Sociological Review, 48:6(1983) 781-795.

W. Goldner, "The Lowry Model Heritage," Journal of the American Institute of Planners, 37:2(1971) 100-110.

B. Harris, B. "The Real Issues Concerning Lee's Requiem," Journal of the American Planning Association, 60:1(1994) 31-34.

B. Harris, "Bridging the Gap between Theory and Practice in Urban Planning," in J.R. Pack, ed., Proceedings of the Conference on the Use of Models by Planning Agencies (Philadelphia: University of Pennsylvania, 1975).

R.H. Haveman, K. Hollenbeck, K. Microeconomic Simulation Models For Public Policy Analysis (New York: Academic Press, 1980).

M. Janowitz, "Sociological Models and Social Policy," ARSP: Archiv für Rechts- und Sozialphilosophie, 55:3(1969) 305-321.

S. Jasanoff, "Contested Boundaries in Policy-Relevant Science," Social Studies of Science, 17:2(1987) 195-230.

R.A. Johnston, T. de la Barra, "Comprehensive Regional Modeling for Long-Range Planning: Linking Integrated Urban Models and Geographic Information Systems,” Transportation Research Part A, 34(2000) 125-136.

L.F. Konikow, J.D. Bredehoeft, "Ground-Water Models Cannot Be Validated," Advances in Water Resources, 15(1992) 75-83.

K.S. Korfmacher, "Water Quality Modeling for Environmental Management: Lessons from the Policy Sciences,” Policy Sciences, 31:1(1998) 35-54.

P.D. Larkey, L.S. Sproull, "Models in Theory and Practice. Some Examples, Problems, and Prospects,” Policy Sciences, 13:3(1981) 233-246.

H.D. Lasswell, A Pre-View of Policy Sciences (New York: American Elsevier, 1971).

B. Latour, S. Woolgar, Laboratory Life: The Construction of Scientific Facts (Beverly Hills: Sage Publications, 1979).

B. Latour, Science in Action: How to Follow Scientists and Engineers through Society (Cambridge: Harvard University Press, 1987).

C. Lawson, "Microsimulation for Urban Transportation Planning," Journal of Urban Technology, 13:1 (2006) 55-80. 
D.B. Jr. Lee, "Requiem for Large-Scale Models," Journal of the American Institute of Planners, 39:3(1973) 163-178.

C. Lefèvre, "Metropolitan Government and Governance in Western Democracies: a Critical Review," International Journal of Urban and Regional Research, 22:1(1998) 9-25.

S. Maasen, P. Weingart, Democratization of Expertise? Exploring Novel Forms of Scientific Advice in Political Decision-Making (Dordrecht: Springer, 2005).

P. Matarasso, "Integrated Assessment Models of Global Change," in T. Munn, M.K. Tolba, eds., Encyclopedia of Global Environmental Change, 4 (New York: Wiley, 2001).

C.W. Mills, "Situated Actions and Vocabularies of Motive," American Sociological Review, 5:6(1940) 904-913.

R.E. Nance, R.G. Sargent, "Perspectives on the Evolution Of Simulation," Operations Research, 50:1(2002) 161-172.

M. Nilsson, A. Jordan, J. Turnpenny, J. Hertin, B. Nykvist, D. Russel, “The Use and Non-use of Policy Appraisal Tools in Public Policy Making: an Analysis of Three European Countries and The European Union,” Policy Sciences, 41:4(2008) 335-355.

OJEU, Directive 2000/60/EC of the European Parliament and of the Council of 23 October 2000 establishing a framework for Community action in the field of water policy, Official Journal of the European Union, 12.22.2000, L 327 1-73.

OJEU, Directive 2008/50/EC of the European Parliament and of the Council of 21 May 2008 on ambient air quality and cleaner air for Europe, Official Journal of the European Union, 11.6.2008, L 152 1-44.

N. Oreskes, K. Shrader-Frechette, K. Belitz, "Verification, Validation, and Confirmation of Numerical Models in the Earth Sciences," Science, New Series, 263:5147(1994) 641-646.

S. Owens, T. Rayner, O. Bina, "New Agendas for Appraisal: Reflections on Theory, Practice, and Research," Environment and Planning A, 36(2004) 1943-1958.

H. Pack, J.R. Pack, "Urban Land-Use Models: the Determinants of Adoption and Use," Policy Sciences, 8:1(1977) 79-101.

J. Pierre, "Models of Urban Governance. The Institutional Dimension of Urban Politics," Urban affairs review, 34:3(1999) 372-396.

S.H. Putnam, Integrated Urban Models. Policy Analysis of Transportation and Land Use, (London: Pion, 1983).

D.A. Schön, M. Rein Frame Reflection: Toward the Resolution of Intractable Policy Controversies (New York: Basic Books, 1994).

C. Seigneur, B. Pun, P. Pai, J.-F. Louis, P. Solomon, C. Emery, R. Morris, M. Zahniser, D. Worsnop, P. Koutrakis, W. White, I. Tombach, "Guidance for the Performance Evaluation of Three-Dimensional Air Quality Modeling Systems for Particulate Matter and Visibility,” Journal of Air \& Waste Management Association, 50(2000) 588-599.

J.P. Shim, M. Warkentin, J.F. Courtney, D.J. Power, R. Sharda, C. Carlsson, "Past, Present, and Future of Decision Support Technology,” Decision Support Systems, 33(2002) 111126.

H.A. Simon, "From Substantive to Procedural Rationality," in S. Latsis, ed., Method and Appraisal in Economics (Cambridge: Cambridge University Press, 1976).

S.L. Star, J.R. Griesemer, "Institutional Ecology, 'Translations' and Boundary Objects: Amateurs and Professionals in Berkeley's Museum of Vertebrate Zoology,” Social Studies of Science, 19:3(1989) 387-420.

P. Todd, I. Benbasat, "The Use of Information in Decision Making: an Experimental Investigation of the Impact of Computer-Based Decision Aids," MIS Quarterly, 16:3(1992) 373-393.

A. Voinov, H.H. Shugart “'Integronsters', Integral and Integrated Modeling,” Environmental Modelling \& Software, 39(2013) 149-158.

M. Wegener, "Operational Urban Models: State of the Art," Journal of the American Planning Association, 60:1(1994) 17-29. 
E. Wenger, "Communities of Practice and Social Learning Systems”, Organization, 2(2000) 225-246.

C.H. Weiss, "The Circuitry of Enlightenment. Diffusion of Social Science Research to Policymakers," Knowledge: Creation, Diffusion, Utilization, 8:2(1987) 274-281.

C.H. Weiss, "Knowledge Creep and Decision Accretion," Knowledge: Creation, Diffusion, Utilization, 1:3(1980) 381-404.

C.H. Weiss, Using Social Research in Public Policy Making (Lexington: Lexington Books, 1977).

K.P. Whyte, R.P. Crease, "Trust, Expertise, and the Philosophy of Science," Synthese, 177(2010) 411-425.

\section{Notes}

${ }^{1}$ At a global scale, integrated modeling dates back to Forrester's models and their use by the Club of Rome at the beginning of the 1970s (Forrester, 2007; Matarasso, 2001). It gave birth to the so-called Integrated Global Modeling approach (IGM), which takes into account energy, industry, agriculture, population and other factors impacting global change. IGM has been of growing importance in the public arena since the 1992 Rio Conference and the work of the International Panel on Climate Change. In particular, there is now increasing use of Earth System Models that combine the atmosphere, the hydrosphere, the cryosphere and terrestrial surfaces, while tracking global cycles such as the energy, water and carbon cycles. As we focus here on urban governance, the technical and political scope of the IGM approach is far from our concerns and we will not take it into consideration.

${ }^{2}$ In our literature review we found several references with misleading titles such as Microeconomic simulation models for public policy analysis (Haveman and Hollenbeck, 1980) or Integrated urban models. Policy analysis of transportation and land use (Putnam, 1983). These books deal with modeling and the "policy analysis" is a mere declaration of intent.

${ }^{3}$ PPA: Plan de Protection de l'Atmosphère de la région Île-de-France.

${ }^{4}$ SDA: Schéma Directeur d'Assainissement de l'agglomération parisienne.

${ }^{5}$ DRIEE: Direction Régionale et Interdépartementale de l’Environnement et de l’Énergie.

${ }^{6}$ SIAAP: Syndicat Interdépartemental pour l'Assainissement de l'Agglomération Parisienne. 